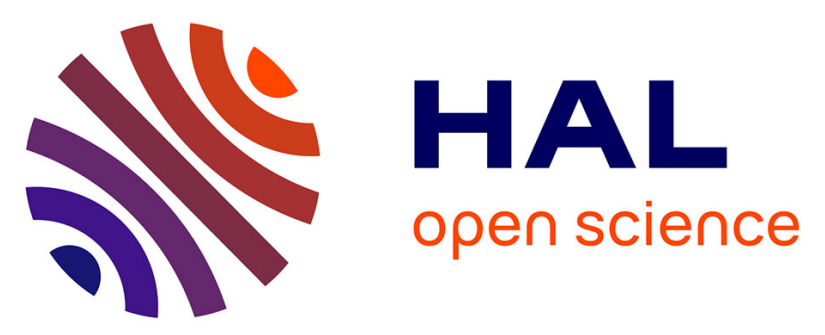

\title{
Middle ear adenomatous neuroendocrine tumours: single institution experience with five cases
}

\author{
Lauranne Alciato, Ghizlène Lahlou, Frédéric Tankéré, Dominique
}

Cazals-hatem, Alexis Bozorg-grayeli, Olivier Sterkers, Daniele Bernardeschi

\section{- To cite this version:}

Lauranne Alciato, Ghizlène Lahlou, Frédéric Tankéré, Dominique Cazals-hatem, Alexis Bozorg-grayeli, et al.. Middle ear adenomatous neuroendocrine tumours: single institution experience with five cases. Clinical Otolaryngology, In press, 10.1111/coa.13791 . hal-03217892

\section{HAL Id: hal-03217892 \\ https://hal.sorbonne-universite.fr/hal-03217892}

Submitted on 5 May 2021

HAL is a multi-disciplinary open access archive for the deposit and dissemination of scientific research documents, whether they are published or not. The documents may come from teaching and research institutions in France or abroad, or from public or private research centers.
L'archive ouverte pluridisciplinaire HAL, est destinée au dépôt et à la diffusion de documents scientifiques de niveau recherche, publiés ou non, émanant des établissements d'enseignement et de recherche français ou étrangers, des laboratoires publics ou privés. 


\title{
Middle ear adenomatous neuroendocrine tumours: single institution experience with five cases
}

\author{
Running title: Middle ear adenoma
}

Lauranne Alciato $\mathrm{MD}^{1}$, Ghizlène Lahlou $\mathrm{MD}^{1}$, Frédéric Tankéré $\mathrm{MD}$, $\mathrm{PhD}^{1}$, Dominique Cazals-Hatem $\mathrm{MD}^{2}$, Alexis Bozorg-Grayeli $\mathrm{MD}, \mathrm{PhD}^{3}$, Olivier Sterkers MD, $\mathrm{PhD}^{1}$, Daniele Bernardeschi MD, $\mathrm{PhD}^{1}$

Authors' institutional affiliation:

${ }^{1}$ APHP, Otology, auditory implants and skull base department, Pitié-Salpêtrière Hospital, Paris, France

${ }^{2}$ APHP, Histopathology department, Beaujon Hospital, Paris, France

${ }^{3}$ Otolaryngology department, Dijon University Hospital and ImVia research laboratory, Bourgogne-Franche-Comté University, France

Corresponding author:

Daniele Bernardeschi MD, PhD

Otology, auditory implants and skull base department, Pitié-Salpêtrière Hospital,

47 Boulevard de l'Hôpital,

75013 Paris, France

Email: daniele.bernardeschi@aphp.fr

Funding information: no funding.

Author contributions' statement:

1. Conception of the work: Lauranne Alciato, Daniele Bernardeschi.

This article has been accepted for publication and undergone full peer review but has not been through the copyediting, typesetting, pagination and proofreading process, which may lead to differences between this version and the Version of Record. Please cite this article as doi: 10.1111/COA.13791

This article is protected by copyright. All rights reserved 
2. Data collection: Lauranne Alciato, Daniele Bernardeschi.

3. Data analysis and interpretation: Lauranne Alciato, Ghizlène Lahlou, Dominique Cazals-Hatem, Daniele Bernardeschi.

4. Drafting the article: Lauranne Alciato, Daniele Bernardeschi.

5. Critical revision of the article: Olivier Sterkers, Frédéric Tankéré, Ghizlène Lahlou, Alexis Bozorg-Grayeli.

6. Final approval of the version to be published: Daniele Bernardeschi.

Data availability statement: The data that support the findings of this study are available from the corresponding author, upon reasonable request. 
DR DANIELE BERNARDESCHI (Orcid ID : 0000-0002-5937-8847)

Article type : Correspondence: Our Experience

Key points:

1. Middle ear adenomatous neuroendocrine tumours are extremely rare causes of middle ear masses. Differential diagnosis is of primary importance to decide on the correct management since they require surgery whereas other lesions can be actively watched.

2. CT and MRI show a non-hypervascular lesion, differentiating it from paraganglioma. It is a mesotympanic lesion that usually encases the ossicles without bone erosion and it can invade the retrotympanum and Eustachian tube.

3. Radical surgery is the treatment of choice. Since middle ear adenomatous neuroendocrine tumours adhere to adjacent structures and lack a tumour capsule, gross total resection is challenging.

4. Late recurrences may be observed and complicated by the development of middle ear cholesteatoma, emphasising the importance of a long follow-up.

5. Recurrence can be associated with neural and intracranial invasion, lymph node or distant metastasis, highlighting the malignant potential of middle ear adenomatous neuroendocrine tumours.

Keywords: MEANT; carcinoid tumour; middle ear adenoma; paraganglioma; schwannoma; cholesteatoma; facial nerve; temporal bone; tympanoplasty; mastoidectomy. 


\section{Introduction}

Middle ear adenomatous neuroendocrine tumours (MEANTs) ${ }^{1,2}$, also known as neuroendocrine adenomas of the middle ear (NAME) $)^{3}$, are very rare causes of middle ear masses of uncertain histogenesis. Only 175 cases of MEANTs have been published, mainly single case reports ${ }^{1,2,4-6}$. As they can present both endocrine/carcinoid and epithelial/glandular histologic features, MEANTs have generated controversy within the literature and have led some early authors to state that carcinoid tumours and adenomas of the middle ear were different entities, not including paraganglioma ${ }^{4,7}$. Positive immunohistochemistry is often observed for a variety of neuroendocrine markers ${ }^{1,2,4}$ and a classification has been proposed based on the presence or absence of these markers and metastasis or carcinoid syndrome ${ }^{4}$. Yet, immunohistochemical markers are nonspecific and can be expressed by other neuroendocrine tumours such as paraganglioma, highlighting the importance of clinical, radiological and histopathological findings for the diagnosis of MEANTs $^{1,2}$. More recently, a multi-institutional retrospective review provided a contemporary analysis and developed a consensus-driven staging system (T/N/M/S) for MEANTs in order to improve our current understanding and management of these tumours ${ }^{1}$.

The aim of this work was to present a case series of five patients with MEANTs and discuss the diagnostic and therapeutic work-up of these extremely rare tumours. 


\section{Materials and methods}

Patients with histologically confirmed MEANT, treated in a single tertiary referral centre, were identified using the histopathological database of rare tumours. Since it was a retrospective and anonymous data collection, authorisation of the ethical board was not required. The reporting guideline STROBE has been followed. Two physicians including one senior surgeon reviewed the patients' medical records for demographics, symptomatology, physical examination with microscopic and endoscopic otoscopy, preoperative pure tone audiometry and preoperative CT and MRI. Facial nerve function was staged following the House-Brackmann grading system. Intraoperative findings were analysed such as surgical approach, involvement of temporal bone spaces and structures (inner ear, facial nerve, vessels, dura), extent of resection and staging following Marinelli's T/N/M/S staging system $^{1}$. According to this classification, tumours are staged as: T1 if they correspond to small tumour limited to the middle ear cavity; T2 if they encase the ossicles (T2a), extend to the mastoid (T2b), or extend through the tympanic membrane (T2c); T3 if they adhere to important neurovascular structures; T4 if there is an intradural extension; N1 and M1 indicate the presence of lymph nodes or distant metastases, respectively; S1 indicates a secreting tumour. Postoperative outcomes were recorded: complications of surgery, facial nerve function, audiological results, recurrence, and duration of follow-up. Data are presented as mean \pm standard deviation (range). Since there were a limited number of cases and because of the descriptive nature of this study, statistical analysis was deemed inappropriate.

This article is protected by copyright. All rights reserved 


\section{Results}

Patients and clinical findings

We identified five patients with MEANT, treated between 2008 and 2019: four presented with primary MEANT and one was previously operated twice elsewhere and presented with recurrent MEANT associated with a cholesteatoma. Patient characteristics and symptomatology are presented in Table 1 . Mean age at surgery was $40 \pm 7$ years (33-49). All patients presented with progressive hearing loss, associated in one case with facial nerve paralysis (grade IV of House-Brackmann scale) and in three cases with aural fullness. No patient presented with carcinoid syndrome. The most common otomicroscopy finding in primary cases was a white/pink retrotympanic and non-pulsatile mass (Fig. 1A), extending to the external auditory canal in one case. One patient had an epitympanic cholesteatoma with a large erosion of the bony epitympanum. The mean pure tone audiometry (calculated from $0.5,1,2$, and $4 \mathrm{kHz}$ frequencies) for air and bone conduction was $38 \pm 18 \mathrm{~dB}$ and $14 \pm 6 \mathrm{~dB}$, respectively. The mean air-bone gap was $25 \pm 16 \mathrm{~dB}$.

Preoperative imaging

CT and MRI were available in all cases. All patients had tumours located in the mesotympanum, encasing the ossicles but without ossicular erosion. There was an extension to the retrotympanum and the sinus tympani in four cases (Fig. 1B), and to the epitympanum in two cases. Tumours also extended to the Eustachian tube and were associated with mastoid retention in two cases (Fig. 2). One patient presented an invasion of the facial nerve to the mastoid portion and a neural spread of the tumour to the tympanic portion, the geniculate ganglion, and the internal auditory canal (Fig. 3A). All tumours presented with mild contrast enhancement on post-contrast T1-weighted MRI sequences, without any radiological sign of hypervascularisation (Fig. 1C).

\section{Surgery}

This consisted of a canal wall-up tympanomastoidectomy with posterior tympanotomy in four cases. The patient with the facial nerve paralysis underwent a combined canal wall-down tympanomastoidectomy and middle cranial fossa approach since the tumour extended to the internal auditory canal. The facial nerve was invaded by the tumour from its mastoid portion to the internal auditory canal and a resection of the facial nerve was performed with immediate cable graft repair using the great auricular nerve. This patient also required stapes removal due to tumour invasion of the oval window, and a temporalis fascia interposition was made. Strong adherence to ossicles was noted in three cases. Two patients 
required malleus and incus removal with partial ossiculoplasty using a Kurz® (Heinz Kurz GmbH Medzintechnik, Dusslingen, Germany) titanium Bell partial ossicular replacement prosthesis. All patients underwent macroscopic gross total resection except one who underwent a near total resection. Following Marinelli's proposed T/N/M/S staging system ${ }^{1}$, tumours were staged as T1 in one case, T2a in two cases, T3 in one case, and T4 in one case.

\section{Pathologic findings}

Histopathologically, the tumours were encapsulated and mostly demonstrated a trabecular or glandular growth pattern in a fibrous stroma. They were composed of cuboidal cells, with round-to-oval hyperchromatic nuclei, and moderate eosinophilic cytoplasm. There was no necrosis or mitotic activity. In the patient with facial nerve involvement, tumour infiltration into the facial nerve was exhibited (Fig. 3B, 3C). Immunophenotypically, the tumours showed positive staining with at least one of the following markers: cytokeratin (CK7, four cases), synaptophysin (four cases) and chromogranin (three cases). The Ki-67 proliferative index was low in all cases $(<3 \%)$.

\section{Postoperative results}

Only one patient experienced postoperative complications: a profound sensorineural hearing loss was found in the patient who required stapes removal. Regarding postoperative audiological results $(n=4$, deafness excluded), the mean pure tone audiometry for air and bone conduction was $32 \pm 24 \mathrm{~dB}$ and $15 \pm 14 \mathrm{~dB}$, respectively, and the mean air bone gap was $18 \pm 15 \mathrm{~dB}$. All patients had normal postoperative facial nerve function except the one with cable graft who recovered up to grade III of House-Brackmann scale at 1 year.

\section{Follow-up}

The mean follow-up was $60 \pm 57$ months (9-129). During follow-up, two patients developed recurrence and required revision surgery. The one with facial nerve invasion presented recurrence 8 years after the previous surgery, with an intracranial extension but not invading the temporal lobe; he underwent revision surgery through a middle cranial fossa approach. Histopathologically, the tumour exhibited the same features as previously described but with a high Ki-67 proliferative index (10 to 20\%). Despite surgery, he developed tumour recurrence with lymph node metastasis in the parotid, staging the tumour as T4N1M0. He underwent radiation therapy (tomotherapy: $60 \mathrm{~Gy}$ to the surgical site, $54 \mathrm{~Gy}$ to the lymph nodes) and the lesions were stable at last follow-up. The other patient, who was initially staged as T3 and underwent a near total resection, developed a recurrence in the middle ear associated with an epitympanic cholesteatoma, 6 years after the first surgery. He 
underwent a revision canal-wall-up tympanomastoidectomy and was disease-free at last follow-up.

This article is protected by copyright. All rights reserved 


\section{Discussion}

\section{Synopsis of key/new findings}

With this case series, we analysed our experience in treating these challenging and extremely rare temporal bone tumours. We found imaging analysis to be particularly interesting in that an invasion of the retrotympanum and Eustachian tube was present in almost all primary cases. The presence of these invasions together with the lack of a tumour capsule and the strong adherence of the tumour to the surrounding structures could explain the tendency for recurrence that has already been reported by other authors ${ }^{1,2,7,8}$. Since these "hidden" areas are difficult to reach, extensive drilling is generally needed to achieve gross total resection.

Another interesting finding that, to our knowledge, has not already been described, is the association between recurrent diseases and the development of middle ear cholesteatoma. The two patients affected by recurrent tumours did not have any previous history of chronic otitis and/or tubal dysfunction so the reason for this association is unclear. It could be stated that the recurrent tumour alters the gas exchange and the drainage of the middle ear and mastoid, thus promoting the occurrence of cholesteatoma.

Recurrent disease is at risk of neural invasion ${ }^{7}$. One of our patients developed a facial palsy due to tumour recurrence, and neural spread of the tumour up to the internal auditory canal was highlighted on MRI. This neural spread was then confirmed by histological examination and, to date, only one case of intraneural invasion has been reported in the English literature ${ }^{7}$ but no case of neural spread has been documented.

Strengths of the study

Although this is a retrospective, single institute case series, the availability of all data with no patient lost to follow-up allowed us to make a robust analysis of this clinical condition. In particular, with reference to imaging and surgical procedures, some interesting information could be obtained from their analysis.

Comparisons with other studies

Most of the published literature consists of case reports. A recent multi-institutional investigation of 32 cases over six referral centres has been published, allowing those authors to propose a classification for this rare disease ${ }^{1}$. We used their classification to stage our patients and we found it particularly useful, especially to understand the spread of the disease and its malignant potential by recurrence, local invasion or metastasis. In our series, both patients staged T3 or T4 developed recurrence and required revision surgery, supporting the 
conclusion of Marinelli et al. that those stages were significantly more difficult to resect and more likely to require multiple revision surgical procedures due to recurrences. The median time to recurrence of Marinelli's cohort was 72 months, which is similar to our findings. They used octreotide scintigraphy for screening of residual/recurrent MEANTs; in one of our recurrent cases, recurrence was clinically evident because of the onset of a facial palsy whereas for the second, the recurrent tumour was found intraoperatively during resection of a cholesteatoma.

Metastatic tumours have been described in other articles, either in lymph nodes (three cases) or distant metastasis (four cases, liver or bone), and three cases of disease-related death have been reported ${ }^{2,8-10}$. According to the literature, and including our case series, local and distant metastasis have been described in about $4 \%$ of cases. They are usually associated with recurrent disease, and therefore with slow-growing tumours. With their classification, Saliba et al. suggested that positive immunohistochemistry was associated with recurrence and metastasis ${ }^{4}$. In our series, all patients had positive immunohistochemistry so this does not appear to be a good indicator of recurrence or malignancy. Our patient with intracranial recurrence and lymph node metastasis in the parotid presented histopathological evidence of malignant potential: first, a locally aggressive tumour with facial nerve infiltration; second, increased mitotic index. Thus, it could be stated that MEANTs could acquire properties of cancer in their natural evolution, leading to a malignant degeneration.

Because of its rarity, the optimal treatment for recurrent or metastatic disease is not known. Some authors have proposed to treat it with radiation therapy, sometimes in association with chemotherapy ${ }^{2,7,8,10}$. These therapies could be recommended in the case of locally progressive tumours or metastasis, non-accessible to complete surgical resection.

Clinical applicability of the study

The suspicion of MEANTs should arise from both clinical examination and imaging. The presence of a white/pink non-pulsatile mesotympanic mass should alert clinicians to the differential diagnosis between MEANTs and more frequently occurring tumours of the middle ear such as temporal bone paraganglioma, which usually presents as a red pulsatile hypotympanic mass, schwannoma or cholesteatoma. Imaging by CT and MRI is mandatory for the diagnosis, showing a non-hypervascular lesion in the middle ear, unlike paraganglioma. Moreover, the absence of restricted diffusion on diffusion-weighted MRI distinguishes it from cholesteatoma. Encasement of the ossicular chain without bone erosion is also a positive argument for MEANTs. Osteolysis should orientated to differential diagnosis or malignant degeneration. Regarding schwannoma, differential diagnosis is more 
difficult since both are non-hypervascular lesions and have a nonspecific contrast enhancement on MRI. Schwannoma of the middle ear could arise from the facial nerve or from the lower cranial nerves. In these cases, the location of the mass together with specific CT findings (enlargement of the Fallopian canal or jugular foramen) could facilitate the diagnosis. Differential diagnosis is of primary importance for the clinician to decide on the correct management, since MEANTs require surgery, ideally with extensive gross total resection, whereas other lesions could also undergo a wait-and-scan policy or radiation therapy.

Since histologic and immunohistochemical features are nonspecific and nonpredictive of malignant transformation, genetic analysis of MEANTs needs to be undertaken to assist with their diagnosis, classification and prognosis, and to improve the understanding of their histogenesis.

Finally, because of the extreme rarity of this tumour, patients suspected of having MEANT should be referred to a neurotological referral centre to receive radical primary surgery. Follow-up should include clinical examination, audiometry and imaging (CT and MRI if some opacity is found on CT) once a year and should be long enough to detect late recurrences. Therapeutics of evolving tumours or metastasis should be discussed in a multidisciplinary team meeting. 


\section{References}

1 Marinelli J.P., Cass S.P., Mann S.E., et al. (2018) Adenomatous Neuroendocrine Tumors of the Middle Ear: A Multi-institutional Investigation of 32 Cases and Development of a Staging System. Otol. Neurotol. 39, e712-e721.

2 Bell D., El-Naggar A.K. \& Gidley P.W. (2017) Middle ear adenomatous neuroendocrine tumors: a 25-year experience at MD Anderson Cancer Center. Virchows Arch. 471, 667672.

3 Torske K.R. \& Thompson L.D. (2002) Adenoma versus carcinoid tumor of the middle ear: a study of 48 cases and review of the literature. Mod. Pathol. 15, 543.

4 Saliba I. \& Evrard A.-S. (2009) Middle ear glandular neoplasms: adenoma, carcinoma or adenoma with neuroendocrine differentiation: a case series. Cases J. 2, 6508.

5 da Luz Martins M., Boutin P., Bozorg-Grayeli A., et al. (2002) [Middle ear adenoma: report of two cases and review of the literature]. Ann. Oto-Laryngol. Chir. Cervico Faciale Bull. Soc. Oto-Laryngol. Hopitaux Paris 119, 337-340.

6 Yadav S.K., Naeem R., Sharma A., et al. (2020) Middle ear adenoma with neuroendocrine differentiation: Report of a rare case. Indian J. Cancer 57, 98-101.

7 Ramsey M.J., Nadol J.B., Pilch B.Z., et al. (2005) Carcinoid Tumor of the Middle Ear: Clinical Features, Recurrences, and Metastases: The Laryngoscope 115, 1660-1666.

8 Mooney E.E., Dodd L.G., Oury T.D., et al. (1999) Middle ear carcinoid: an indolent tumor with metastatic potential. Head Neck J. Sci. Spec. Head Neck 21, 72-77.

9 Fundakowski C.E., Chapman J.R. \& Thomas G. (2013) Middle ear carcinoid with distant osseous metastasis. The Laryngoscope 123, 779-782.

10 Pellini R., Ruggieri M., Pichi B., et al. (2005) A case of cervical metastases from temporal bone carcinoid. Head Neck 27, 644-647. 


\section{Conflict of interest}

Non declared.

This article is protected by copyright. All rights reserved 


\section{Tables}

Table 1. Characteristics of the five patients studied.

Pt: patient; M: male; F: female; R: right; L: left; HB: House-Brackmann scale; EAC: external auditory canal; AC: air conduction; ABG: air bone gap; CWD: canal wall-down; CWU: canal wall-up; GTR: gross total resection; NTR: near total resection.

$\dagger$ : Following Marinelli's proposed T/N/M/S staging system ${ }^{1}$. 


\section{Figure legends}

Figure 1. Preoperative otoscopy (A), axial CT (B), and MRI (C) of a MEANT staged T2a. Otoscopy showed a white/pink, non-pulsatile, retrotympanic mass. Imaging showed a tumour located in the mesotympanum (white arrow) with extension to the retrotympanum (black arrow). MRI showed mild contrast enhancement on post-contrast T1-weighted MRI sequence (white arrow).

Figure 2. Preoperative CT (A) and MRI (B) showing a tumour staged T2a, extending to the Eustachian tube (black arrow) and hypotympanum (white arrow); retention in mastoid air cells secondary to antral obstruction is highlighted (white star).

Figure 3. Evidence of facial nerve invasion by the tumour.

A. Preoperative post-contrast T1-weighted MRI sequence (3D multiplanar reconstruction) showing contrast enhancement demonstrating neural invasion and spread of the tumour through the facial nerve (black arrows) from the mastoid portion (white arrow) to the internal auditory canal (black star). IAC: internal auditory canal; SS: sigmoid sinus.

B, C. Histopathological findings (haematoxylin and eosin stains) showing tumour infiltration (black arrows) of the facial nerve (black star). Microscopic features of middle ear adenomatous neuroendocrine tumours can be observed: various growth patterns (trabecular, glandular and infiltrative) associated with fibrous stroma in the background; tumour cells containing round-to-oval hyperchromatic nuclei and moderate eosinophilic cytoplasm. 


\begin{tabular}{|c|c|c|c|c|c|c|c|c|c|c|c|c|c|c|c|c|c|}
\hline Pt & Sex & $\begin{array}{l}\text { Age at } \\
\text { surgery } \\
\text { (years) }\end{array}$ & Side & $\begin{array}{l}\text { Tumor } \\
\text { status }\end{array}$ & Symptoms & Otoscopy & $\begin{array}{l}\text { Preop. } \\
\text { AC (dB) }\end{array}$ & $\begin{array}{l}\text { Preop. } \\
\text { ABG } \\
\text { (dB) }\end{array}$ & $\begin{array}{c}\text { Surgical } \\
\text { approach and } \\
\text { ossicular } \\
\text { reconstruction }\end{array}$ & $\begin{array}{l}\text { Extent of } \\
\text { resection }\end{array}$ & $\begin{array}{l}\text { Tumor } \\
\text { staget }\end{array}$ & $\begin{array}{l}\text { Postop. } \\
\text { AC (dB) }\end{array}$ & $\begin{array}{l}\text { Postop. } \\
\text { ABG (dB) }\end{array}$ & Recurrence & $\begin{array}{l}\text { Additional } \\
\text { treatment }\end{array}$ & $\begin{array}{c}\text { Status at } \\
\text { last contact }\end{array}$ & $\begin{array}{l}\text { Follow- } \\
\text { up } \\
\text { (months) }\end{array}$ \\
\hline$\# 1$ & $M$ & 33 & $R$ & Recurrent & $\begin{array}{c}\text { Progressive } \\
\text { hearing loss, } \\
\text { facial nerve } \\
\text { paralysis } \\
\text { (grade IV) }\end{array}$ & $\begin{array}{c}\text { Epitympanic } \\
\text { cholesteatoma }\end{array}$ & 61 & 46 & $\begin{array}{l}\text { CWD + middle } \\
\text { cranial fossa } \\
\text { approach }\end{array}$ & GTR & T4 & $\begin{array}{c}\text { Deafnes } \\
\mathrm{s}\end{array}$ & Deafness & $\begin{array}{l}\text { Two recurrences with } \\
\text { lymph node metastasis } \\
\text { in the parotid }\end{array}$ & $\begin{array}{c}\text { Surgery, } \\
\text { radiotherapy }\end{array}$ & $\begin{array}{l}\text { Stable } \\
\text { disease }\end{array}$ & 129 \\
\hline$\# 2$ & $M$ & 41 & $R$ & Primary & $\begin{array}{c}\text { Aural } \\
\text { fullness }\end{array}$ & Polyp in EAC & 48 & 24 & $\begin{array}{l}\mathrm{CWU}+\text { partial } \\
\text { ossicular chain } \\
\text { reconstruction }\end{array}$ & NTR & T3 & 61 & 26 & $\begin{array}{c}\text { One recurrence with } \\
\text { epitympanic } \\
\text { cholesteatoma }\end{array}$ & Surgery & $\begin{array}{l}\text { No evidence } \\
\text { of disease }\end{array}$ & 115 \\
\hline$\# 3$ & $\mathrm{~F}$ & 46 & $\mathrm{R}$ & Primary & $\begin{array}{c}\text { Progressive } \\
\text { hearing loss, } \\
\text { aural } \\
\text { fullness }\end{array}$ & $\begin{array}{l}\text { Mass behind a } \\
\text { normal } \\
\text { tympanic drum }\end{array}$ & 20 & 8 & CWU & GTR & T1 & 15 & 6 & No & None & $\begin{array}{l}\text { No evidence } \\
\text { of disease }\end{array}$ & 9 \\
\hline$\# 4$ & $\mathrm{~F}$ & 34 & L & Primary & $\begin{array}{c}\text { Progressive } \\
\text { hearing loss, } \\
\text { aural } \\
\text { fullness }\end{array}$ & $\begin{array}{l}\text { Mass behind a } \\
\text { normal } \\
\text { tympanic drum }\end{array}$ & 21 & 11 & CWU & GTR & T2a & 11 & 4 & No & None & $\begin{array}{l}\text { No evidence } \\
\text { of disease }\end{array}$ & 25 \\
\hline$\# 5$ & $M$ & 49 & $R$ & Primary & $\begin{array}{l}\text { Progressive } \\
\text { hearing loss }\end{array}$ & $\begin{array}{l}\text { Mass behind a } \\
\text { normal } \\
\text { tympanic drum }\end{array}$ & 41 & 34 & $\begin{array}{l}\mathrm{CWU}+\text { partial } \\
\text { ossicular chain } \\
\text { reconstruction }\end{array}$ & GTR & T2a & 41 & 34 & No & None & $\begin{array}{l}\text { No evidence } \\
\text { of disease }\end{array}$ & 20 \\
\hline
\end{tabular}

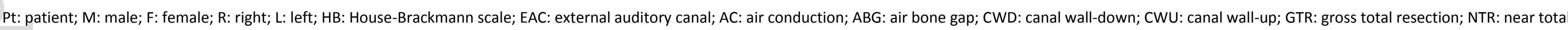
resection.

t: Following Marinelli's proposed T/N/M/S staging system ${ }^{1}$. 


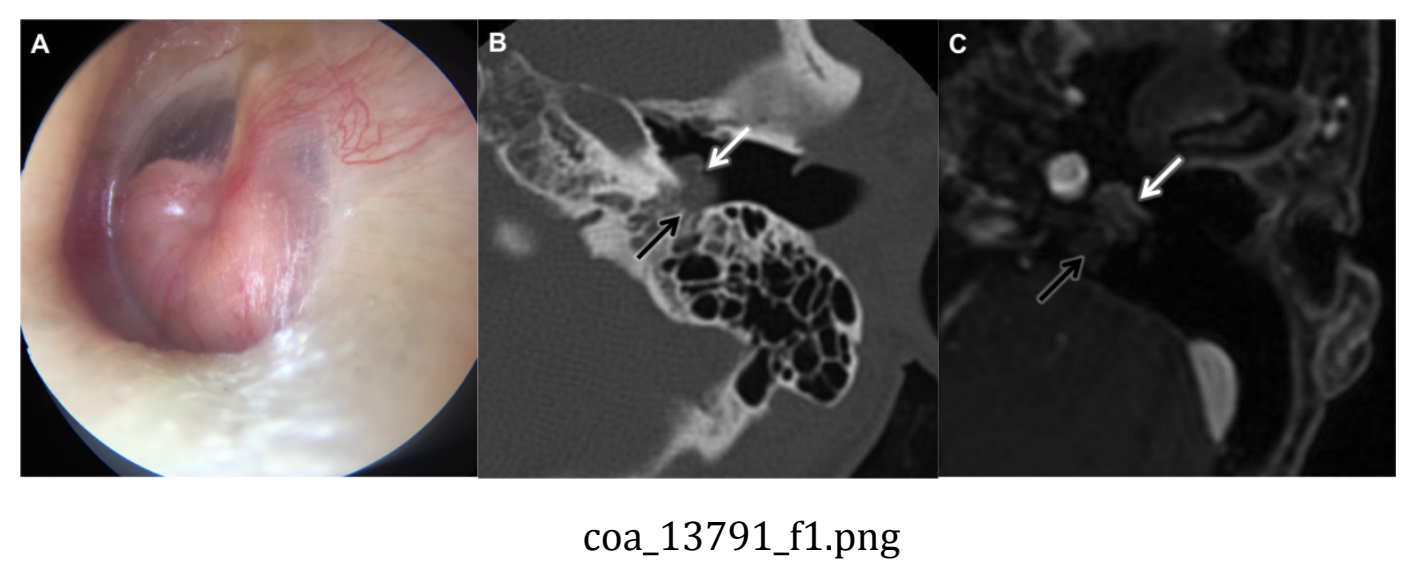

This article is protected by copyright. All rights reserved 


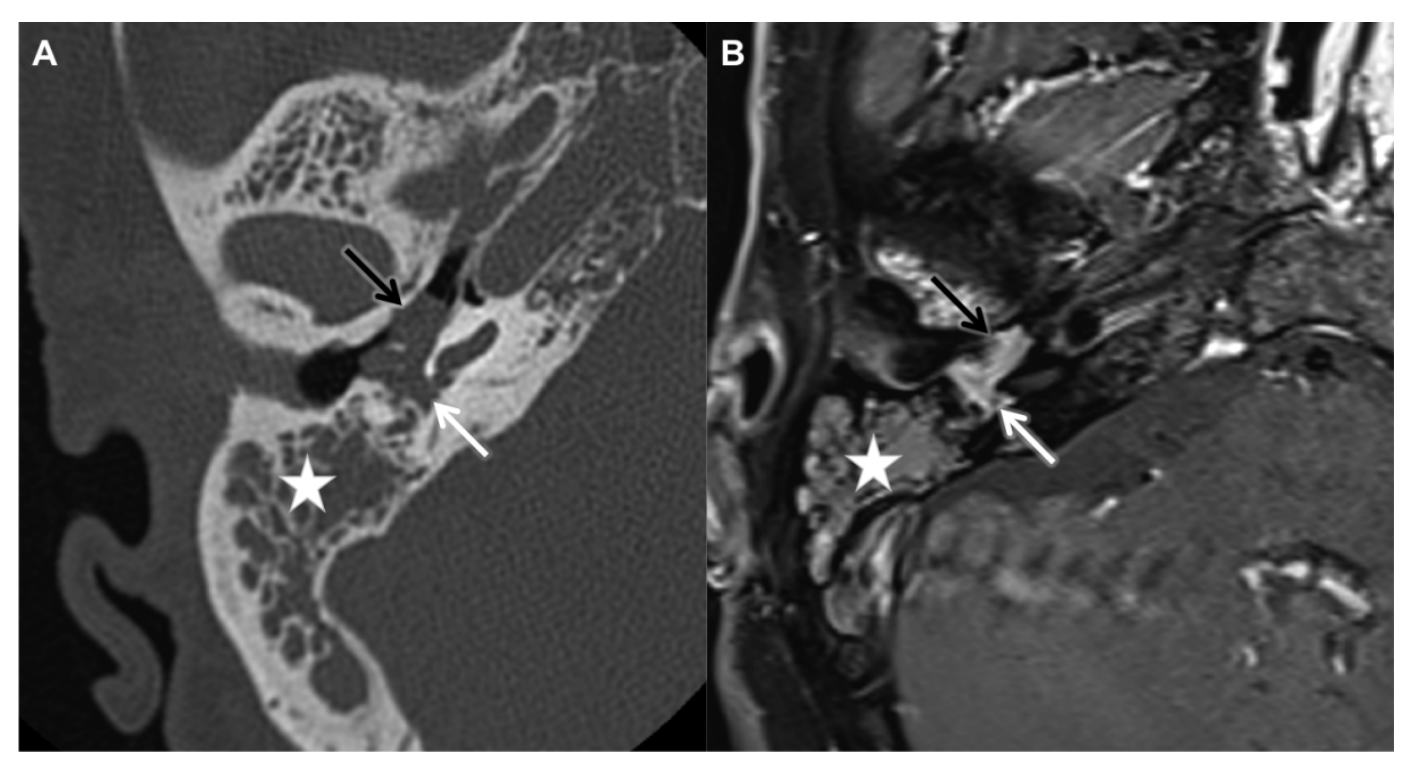

coa_13791_f2.png 


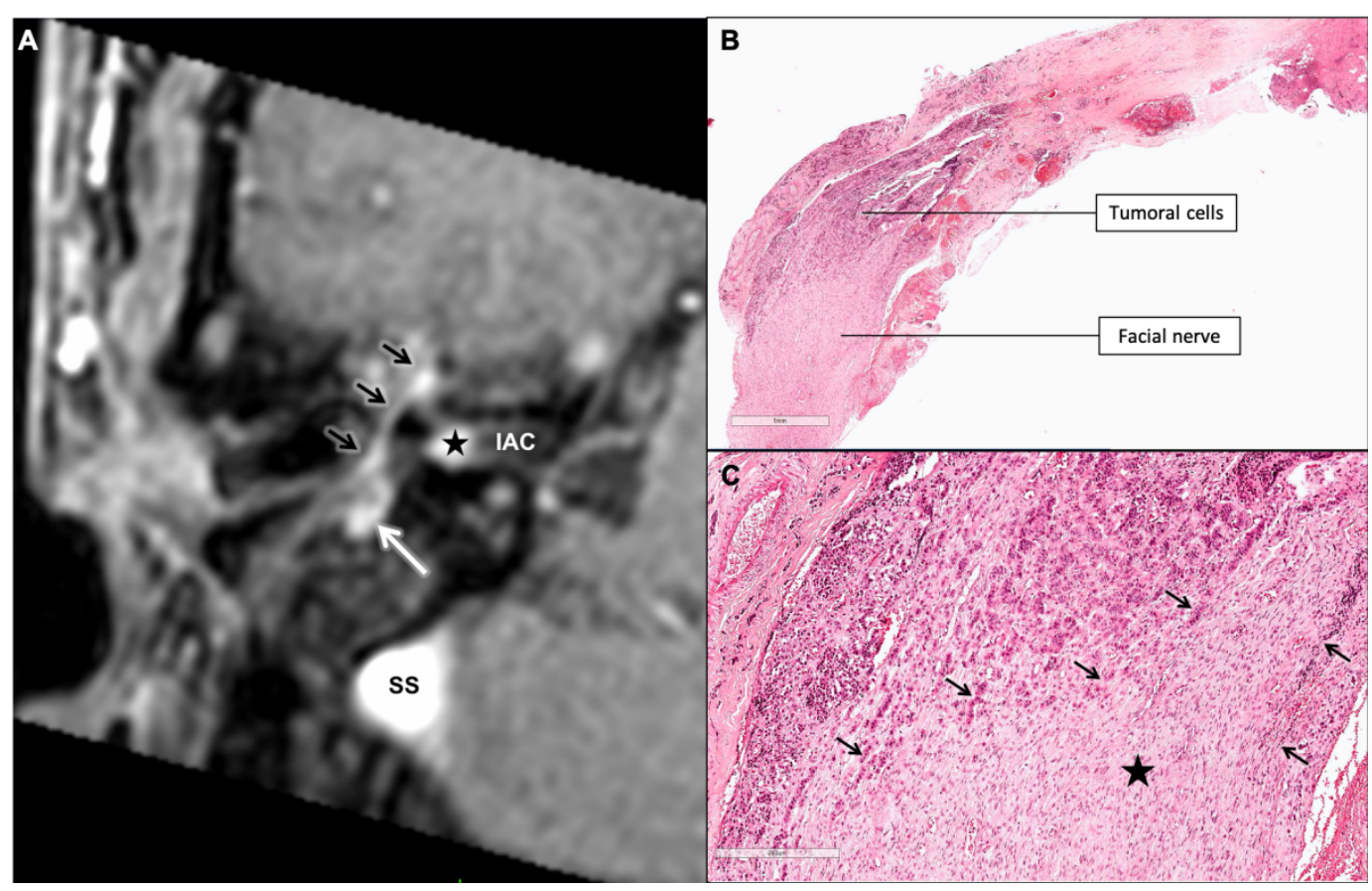

coa_13791_f3.png

This article is protected by copyright. All rights reserved 